\title{
Knockdown of MACC1 expression increases cisplatin sensitivity in cisplatin-resistant epithelial ovarian cancer cells
}

\author{
RUITAO ZHANG, HUIRONG SHI, FANG REN, XIA LI, MINGHUI ZHANG, WEI FENG and YANYAN JIA \\ Department of Gynaecology, First Affiliated Hospital, Zhengzhou University, Zhengzhou, Henan 450052, P.R. China
}

Received October 21, 2015; Accepted December 2, 2015

DOI: $10.3892 /$ or.2016.4585

\begin{abstract}
Abnormal expression of metastasis-associated in colon cancer 1 (MACC1) was found to be closely associated with several types of malignant tumors. The present study aimed to verify the relationship between MACC1 and cisplatin resistance in ovarian cancer cells and the possible mechanisms, which was implemented by inhibition of the expression of MACC1 in cisplatin-resistant human ovarian cancer cell lines A2780/DDP and COC1/DDP. MACC1 shRNA eukaryotic plasmids and negative control plasmids were transfected into A2780/DDP and COC1/DDP cells, respectively, while A2780/DDP and COC1/DDP cells were used as blank controls. Western blotting and sqRT-PCR were used to detect the expression of MACC1 in the different cell groups. Different concentrations of cispaltin $(0,10,20,30,40,50$ and $60 \mu \mathrm{mol} / \mathrm{l})$ were used to treat the cell groups, respectively, and then the chemosensitivity of cisplatin and cell apoptosis were examined by MTT and flow cytometry, respectively. The activity of caspase-3 was determined by spectrophotometry. Expression levels of p-ERK1/2, permeability glycoprotein (P-gp), B-cell lymphoma 2(Bcl-2), Bcl- $\mathrm{X}_{\mathrm{L}}$, Bax and Bad protein were detected in the different ovarian cancer cells by western blotting. After MACC1 knockdown, the chemosensitivity of cisplatin in the ovarian cancer cells was enhanced, and the cell growth inhibition and apoptosis rates were increased. The expression levels of Bax and Bad were upregulated, the activity of caspase-3 was increased, while the expression levels of p-ERK1/2, P-gp, $\mathrm{Bcl}-2$ and $\mathrm{Bcl}-\mathrm{X}_{\mathrm{L}}$ were downregulated as a result of MACC1 inhibition. These results indicate that inhibition of MACC1 improves the chemosensitivity of cisplatin in epithelial ovarian cancer cells, through the regulation of the ERK1/2 signaling pathway on P-gp and its downstream apoptosis proteins.
\end{abstract}

Correspondence to: Professor Huirong Shi, Department of Gynaecology, First Affiliated Hospital, Zhengzhou University, 1 Jian She Road, Zhengzhou, Henan 450052, P.R. China

E-mail: huirongshizzu@yahoo.com

Key words: metastasis-associated in colon cancer 1, ovarian epithelial cancer, cisplatin resistance, chemosensitivity, apoptosis

\section{Introduction}

Epithelial ovarian cancer (EOC) is commonly detected at a late stage, and is commonly diagnosed with abdominal ascites and widespread intraperitoneal dissemination. Aggressive cytoreductive surgery, if possible, is the primary clinical treatment for advanced ovarian cancer $(1,2)$. Platinum and paclitaxel combination chemotherapy or i.p. cisplatin based-chemotherapy is used as a first-line neoadjuvant before cytoreductive surgery or adjuvant treatment after surgery $(3,4)$. Most patients develop platinum chemoresistance or multi-drug resistance during the chemotherapy progress, which is a major obstacle for chemotherapy in ovarian cancer patients (5). Therefore, the identification of platinum-resistance mechanisms and the exploration of chemoresistance reversing therapeutic targets for human EOC are required.

MACC1 was found to be overexpressed in colon cancer, gastric carcinoma, lung cancer, hepatocellular carcinoma and ovarian cancer, and may be used as a biomarker for the poor prognosis and the high risk of metastasis in these malignant tumors (6-10). It was found that downregulation of MACC1 by siRNA sensitized pancreatic cancer cells to gemcitabine treatment, which may be involved in the inhibition of the Ras/ERK signaling pathway (11). Another study showed that knockdown of MACC1 enhanced the apoptosis and growth inhibitory rates of human glioblastoma cells, and could increase glioblastoma cell sensitivity to cisplatin chemotherapy (12). These data indicated that, in addition to invasion and metastasis, MACC1 may also play other unknown roles in the pathological processes of cancer cells, such as chemoresistance.

Herein, we hypothesized that MACC1 may be implicated in the chemoresistance of cisplatin in ovarian cancer. To verify this hypothesis, we inhibited the expression of MACC1 in cisplatin-resistant ovarian cancer A2780/DDP and COC1/DDP cells by RNA interference. Chemosensitivity and the apoptosis rate in different ovarian cancer cells were determined following treatment with different concentrations of cisplatin. Expression levels of apoptosis-associated proteins and caspase-3 activity were assessed. The relationship between $\mathrm{MACC1}$ and cisplatin resistance was investigated.

\section{Materials and methods}

Cell transfection. Human ovarian carcinoma A2780/DDP and COC1/DDP cells were purchased from the China Center 
for Type Culture Collection (Wuhan, China), and cultured in complete RPMI-1640 medium (Hyclone, Logan, UT, USA), at $37^{\circ} \mathrm{C}$ in $5 \% \mathrm{CO}_{2}$. Cells were harvested in the logarithmic phase of growth for all experiments as described below. Recombinant MACC1-psuper-EGFP-shRNA eukaryotic plasmids and the negative control plasmid, as constructed in our previous study (13), were transfected into the A2780/DDP and $\mathrm{COC1/DDP}$ cells, respectively, which was performed following the protocol of Lipofectamine 2000 reagent (Invitrogen, Carlsbad, CA, USA). Stably transfected A2780/DDP and COC1/DDP cells were isolated by G418 (Sigma, St. Louis, MO, USA). Three cell groups used for the next research steps were named: blank control cells (B), negative control cells (NC) and MACC1-knockdown cells (M).

$s q R T-P C R$. Cell total RNA was isolated using TRIzol reagent (Invitrogen), and first strand cDNA was synthesized from $1 \mu \mathrm{g}$ total RNA according to the protocol of the RevertAid First Strand cDNA Synthesis kit (Fermentas, EU). Primers used in the sqRT-PCR were MACC1, 5'-CCTTCGTGGTAATAATGC TTCC-3' (sense) and 5'-AGGGCTTCCATTGTATTGAGGT-3' (antisense); and $\beta$-actin, 5'-ACGCACCCCAACTACAACTC-3' (sense) and 5'-TCTCCTTAATGTCACGCACGA-3' (antisense). PCR cycling parameters (19 cycles) were: denaturation $\left(94^{\circ} \mathrm{C}\right.$ for $\left.30 \mathrm{sec}\right)$, annealing $\left(56^{\circ} \mathrm{C}\right.$ for $\left.30 \mathrm{sec}\right)$ and extension $\left(72^{\circ} \mathrm{C}\right.$ for $\left.30 \mathrm{sec}\right)$. Equal amounts of PCR products were electrophoresed on $1.2 \%$ agarose gels and visualized by ethidium bromide staining. The specific bands of the PCR products were analyzed by Image-Pro Plus 6.0 system, and $\beta$-actin was used as a control for normalization. sqRT-PCR was performed three times independently.

Western blot analysis. The antibodies used in the western blotting, following the manufacturer's protocols, included rabbit anti-human polyclonal MACC1 (Sigma), rabbit anti-human polyclonal phospho-ERK1/2 and mouse anti-human monoclonal P-gp (Santa Cruz Biotechnology, Santa Cruz, CA, USA), rabbit anti-human polyclonal Bcl-2, rabbit anti-human monoclonal Bcl-X $\mathrm{L}_{\mathrm{L}}$, mouse anti-human monoclonal Bax, and rabbit anti-human polyclonal Bad (Beyotime Biotechnology, Haimen, Jiangsu, China). Total protein was extracted using RIPA lysis buffer for western blot analysis and IP (Beyotime Biotechnology), and the protein concentration was determined using Bradford assay. Equal amounts of protein $(30 \mu \mathrm{g})$ were separated by $10 \%$ SDS-PAGE and transferred onto PVDF membranes. The detection of hybridized protein was performed by enhanced chemiluminescence kit (Zhongshan Goldenbridge Biotechnology, Peking, China), and $\beta$-actin was used as a control for normalization. The relative values of the specific bands were analyzed by Image-Pro Plus 6.0 system three times independently.

MTT assay. Cells were planted ( $1 \times 10^{4}$ cells/well) into 96-well plates, and $100 \mu \mathrm{l}$ complete RPMI-1640 medium containing $10 \%$ FBS was added into each well. Three duplicate wells were set up for each group. The cells were cultured for $24 \mathrm{~h}$, and then medium containing cisplatin at $0,10,20,30,40$, 50 , and $60 \mu \mathrm{mol} / 1$, respectively was added. The cells were incubated for $48 \mathrm{~h}$, and the previous medium was replaced by $100 \mu \mathrm{l}$ complete RPMI-1640 medium in each well. After $24 \mathrm{~h}$,
$20 \mu \mathrm{l} \mathrm{MTT}$ reagent $(5 \mathrm{mg} / \mathrm{ml}$; Sigma) was added into each well. Cells were then incubated for another $4 \mathrm{~h}$ and then the former medium was aspirated and $150 \mu \mathrm{l}$ DMSO was added. The absorbance of the sample was measured by a microplate spectrophotometer (Thermo Spectronic, Madison, WI, USA) at $492 \mathrm{~nm}$. All experiments were conducted in triplicate. Cell growth inhibition rate and the half inhibitory concentration $\left(\mathrm{IC}_{50}\right)$ value of cisplatin (LOGIT assay) were calculated. Cell growth inhibition rate $=(1-$ sample OD/control OD $) \times 100 \%$.

Flow cytometric analysis. Every cell group was captured for $48 \mathrm{~h}$ in medium containing cisplatin at $0,10,20,30,40,50$ and $60 \mu \mathrm{mol} / 1$, respectively. The cells were incubated for another $24 \mathrm{~h}$ with complete RPMI-1640 medium. Approximately $1 \times 10^{6}$ cells were treated into a single-cell suspension with PBS solution, and were prepared following the manufacturer's protocol in the Annexin V-FITC Apoptosis Detection kit (Beyotime Biotechnology). Then, rates of apoptosis were analyzed with FACScan system (BD Biosciences, San Jose, CA, USA).

Caspase-3 activity assay. Every cell group was cultured for $48 \mathrm{~h}$ in medium containing cisplatin at $0,10,20,30,40$, 50 and $60 \mu \mathrm{mol} / 1$, respectively, and then incubated for another $24 \mathrm{~h}$ with completed RPMI-1640 medium. Approximately $1 \times 10^{6}$ cells were collected, total protein was extracted using RIPA lysis buffer for western blot analysis and IP (Beyotime Biotechnology), and the protein concentration was controlled using Bradford assay (between 1 to $3 \mathrm{mg} / \mathrm{ml}$ as requested). Equal volumes of protein $(50 \mu \mathrm{l})$ were prepared following the manufacturer's protocol in the Caspase-3 Activity Detection kit (Beyotime Biotechnology). The absorbance values were measured by a microplate spectrophotometer (Thermo Spectronic) at $405 \mathrm{~nm}$. The pyrolysis liquid without the cell samples was used as a blank control. The value of $\Delta \mathrm{A} 405$ (absorbance value of sample at $405 \mathrm{~nm}$ minus absorbance value of blank control at $405 \mathrm{~nm}$ ) represents the activity of caspase-3. All experiments were performed in triplicate.

Statistical analysis. Average values are expressed as mean \pm standard deviation (SD). Measurement data were analyzed by one-way ANOVA, non-parametric test and Bonferroni test using SPSS 17.0 software package. A difference was considered significant at $\mathrm{P}<0.05$.

\section{Results}

MACC1 mRNA and protein expression is altered after RNA interference. As a result of MACC1 knockdown, significant downregulation of MACC1 was observed in the A2780/DDP-M and COC1/DDP-M cells $(\mathrm{P}<0.05)$. No differences were noted between the A2780/DDP-B and A2780/DDP-NC cells, and between the COC1/DDP-B and COC1/DDP-NC cells (Fig. 1).

Suppression of cell proliferation after MACC1 knockdown. After incubation with different concentrations of cisplatin, cell growth inhibition rates were obviously increased in the A2780/DDP-M and COC1/DDP-M cells $\left(\chi^{2}=9.029, \mathrm{P}=0.011\right.$; $\left.\chi^{2}=6.226, \mathrm{P}=0.044\right)$. With higher concentrations of cisplatin, 

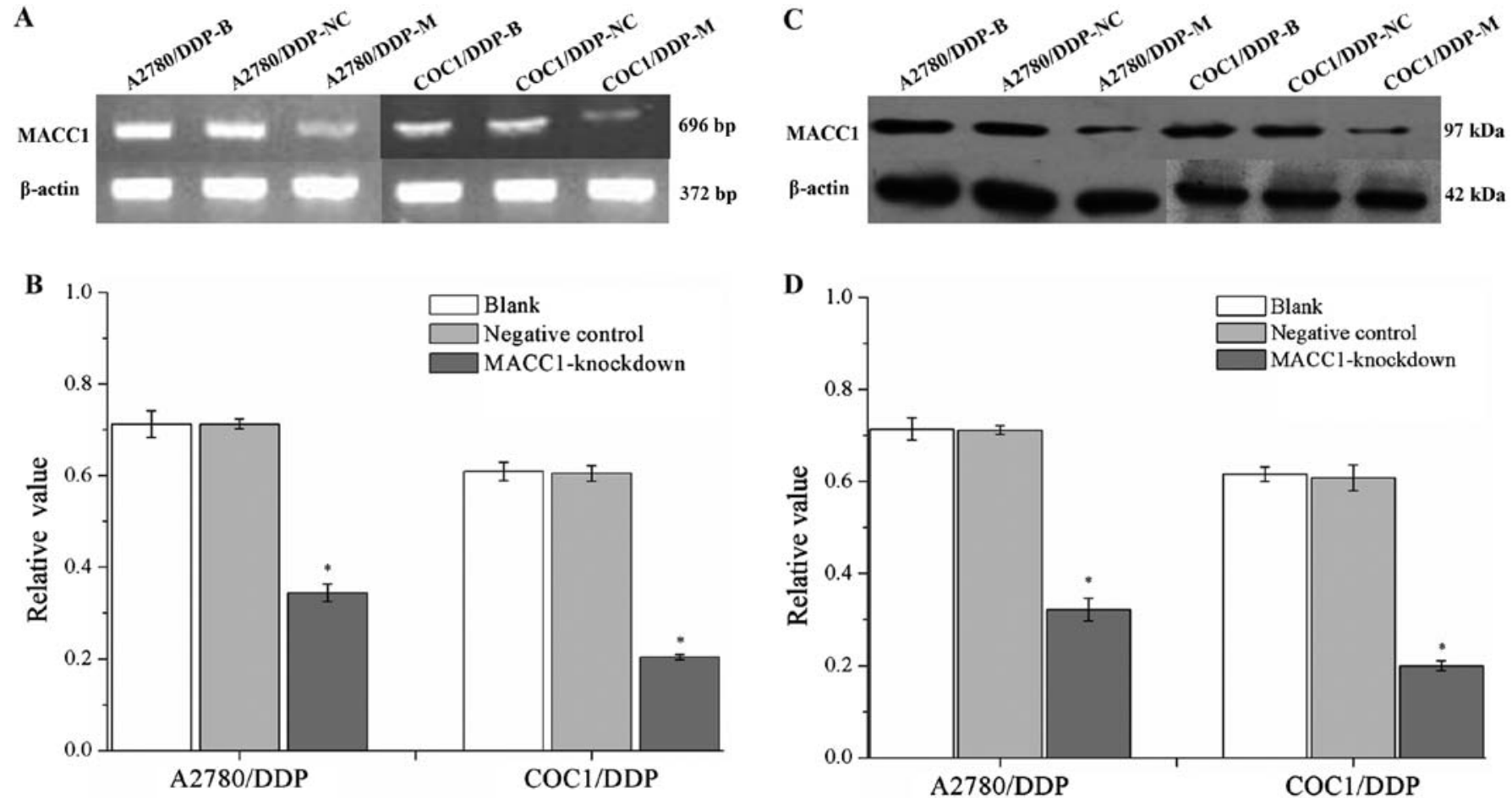

Figure 1. Expression levels of MACC1 mRNA and protein as detected by sqRT-PCR and western blotting in the different cell groups. (A) Expression of MACC1 mRNA as detected by sqRT-PCR in the different cell groups. (B) Histogram shows the relative values of MACC1 mRNA as measured by sqRT-PCR. Each bar represents the mean \pm SD. ${ }^{*} \mathrm{P}<0.05$ compared with the blank and negative control groups. (C) Expression of MACC1 protein as detected by western blotting in the different cell groups. (D) Histogram shows the relative values of MACC1 protein as measured by western blotting. Each bar represents the mean \pm SD. ${ }^{*} \mathrm{P}<0.05$ compared with the blank and negative control groups.
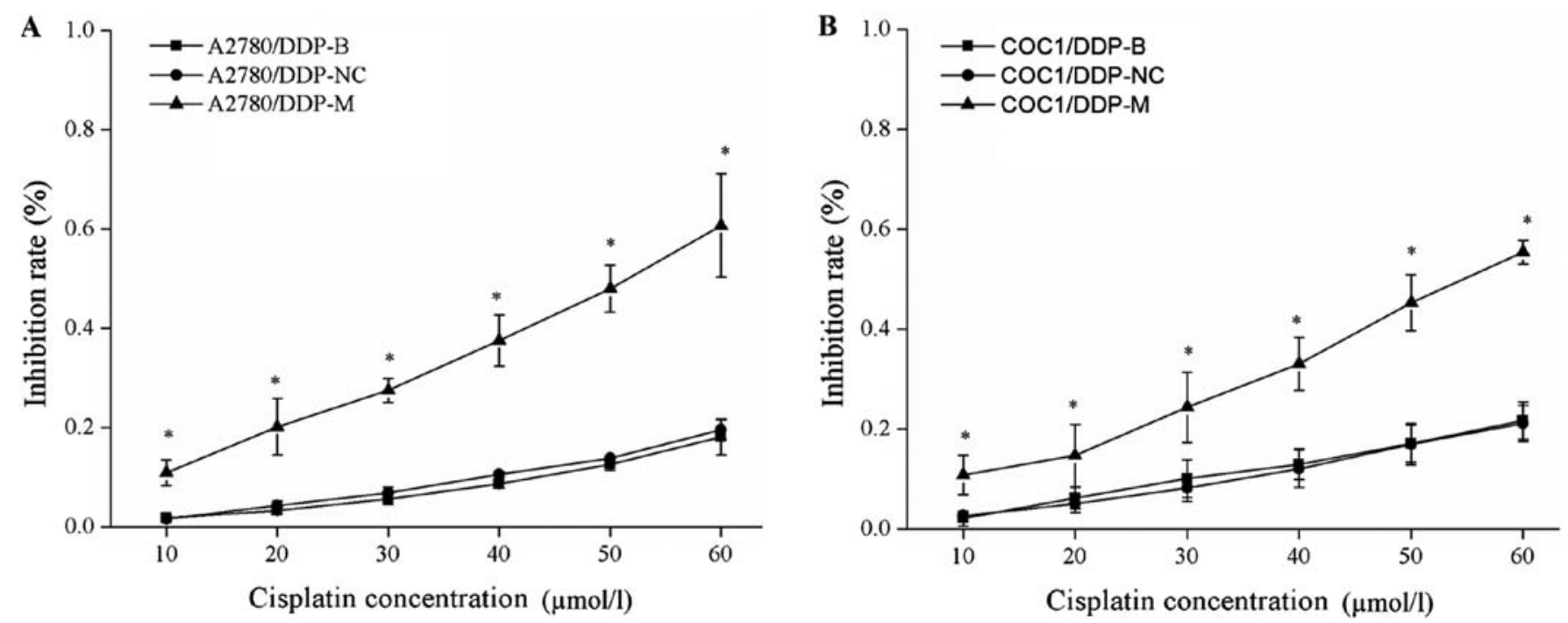

Figure 2. Cell growth inhibition rates as measured by MTT assay in the different cell groups following treatment with different concentrations of cisplatin, respectively. (A) Line graph represents the cell growth inhibition rates in the different A2780/DDP cells. Each bar represents the mean $\pm \mathrm{SD}$. ${ }^{*} \mathrm{P}<0.05$ compared with the blank and negative control groups. (B) Line graph represents the cell growth inhibition rates in different COC1/DDP cells. Each bar represents the mean $\pm \mathrm{SD}$. " $\mathrm{P}<0.05$ compared with the blank and negative control groups.

increased rates of cell growth inhibition were noted $(\mathrm{P}<0.05)$. No differences were found between the A2780/DDP-B and A2780/DDP-NC cells, between the COC1/DDP-B and COC1/DDP-NC cells (Fig. 2).

In addition, the $\mathrm{IC}_{50}$ values of $\mathrm{A} 2780 / \mathrm{DDP}-\mathrm{M}$ and COC1/DDP-M cells for cisplatin were obviously decreased compared with the control cells $(\mathrm{F}=22.760, \mathrm{P}=0.002$; $\left.\chi^{2}=6.489, \mathrm{P}=0.039\right)$. No differences were noted between the A2780/DDP-B and A2780/DDP-NC cells, and between the COC1/DDP-B and COC1/DDP-NC cells (Fig. 3).

Cell apoptosis is induced by RNA interference. After incubation with different concentrations of cisplatin, the cell apoptosis rates were markedly increased in the A2780/DDP-M 

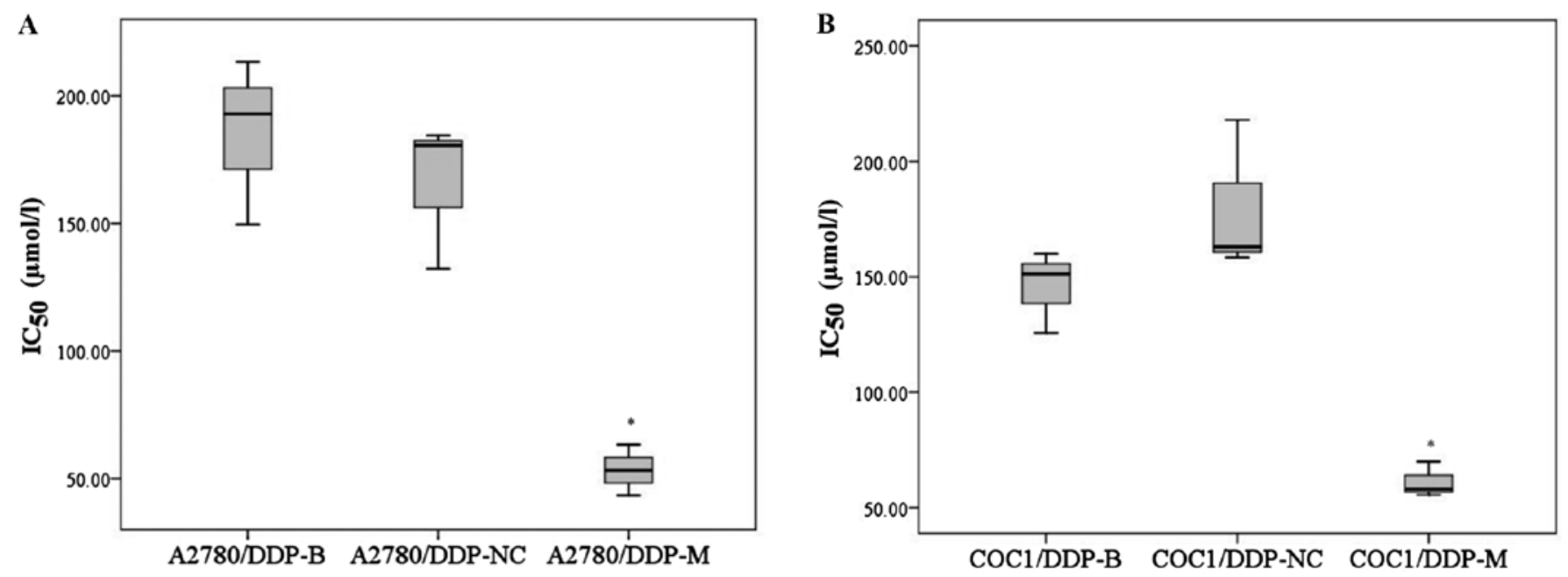

Figure 3. Cisplatin $\mathrm{IC}_{50}$ values as determined by MTT assay in the different cell groups following treatment with different concentrations of cisplatin, respectively. (A) Box plots represent the $\mathrm{IC}_{50}$ values in the different $\mathrm{A} 2780 / \mathrm{DDP}$ cells. Each bar represents the mean $\pm \mathrm{SD}$. ${ }^{*} \mathrm{P}<0.05$ compared with the blank and negative control groups. (B) Box plots represent the $\mathrm{IC}_{50}$ values in the different $\mathrm{COC} 1 / \mathrm{DDP}$ cells. Each bar represents the mean $\pm \mathrm{SD}$. "P<0.05 compared with the blank and negative control groups.
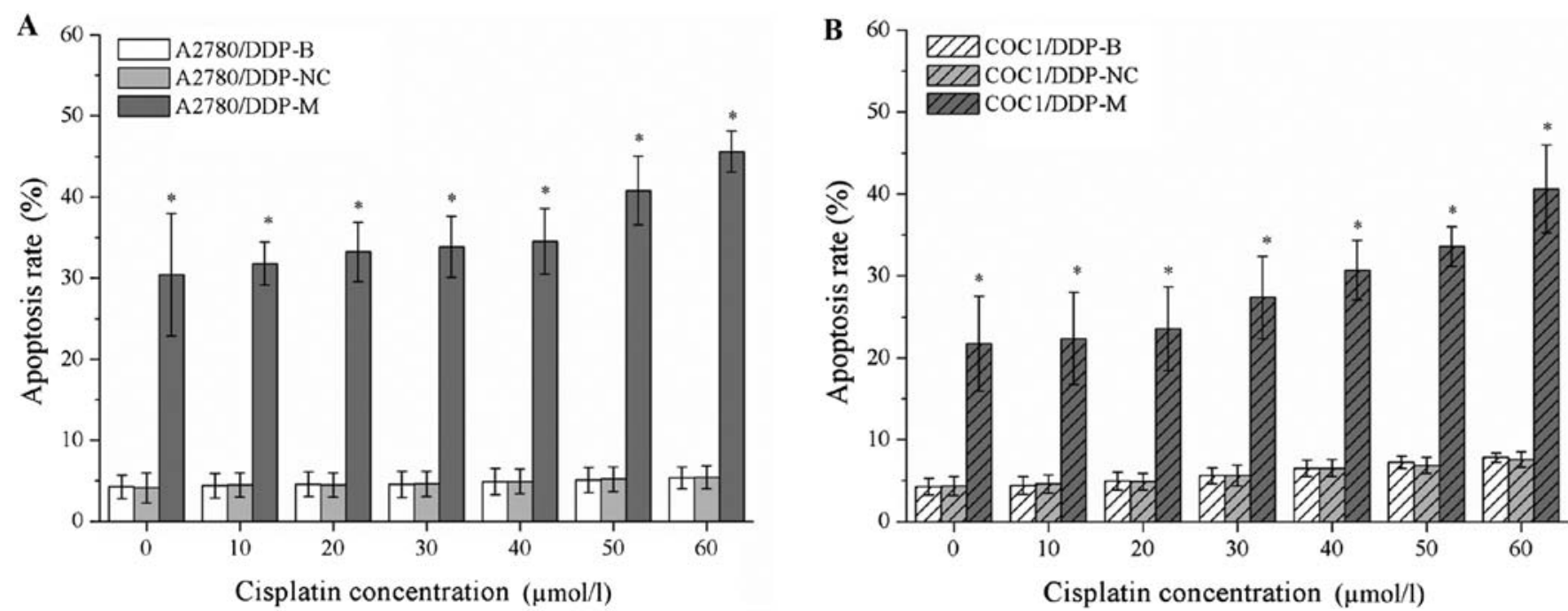

Figure 4. Cell apoptosis rates as determined by flow cytometry in the different cell groups following treatment with different concentrations of cisplatin, respectively. (A) Histogram represents apoptosis rates in the different A2780/DDP cells. Each bar represents the mean \pm SD. "P $<0.05$ compared with the blank and negative control groups. (B) Histogram represents the apoptosis rates in the different COC1/DDP cells. Each bar represents the mean \pm SD. ${ }^{*} \mathrm{P}<0.05$ compared with the blank and negative control groups.

and COC1/DDP-M cells $\left(\chi^{2}=41.375, \mathrm{P}=0.000 ; \chi^{2}=41.362\right.$, $\mathrm{P}=0.000$ ). For a higher concentration of cisplatin, greater rates of cell apoptosis were observed $(\mathrm{P}<0.05)$. No differences were noted between the A2780/DDP-B and A2780/DDP-NC cells, and between the COC1/DDP-B and COC1/DDP-NC cells (Fig. 4).

Expression of p-ERK1/2, P-gp, Bcl-2, Bcl- $X_{L}$, Bax and Bad in the different cell groups. After MACC1 knockdown, obvious downregulation of p-ERK1/2, P-gp, Bcl-2 and Bcl- $\mathrm{X}_{\mathrm{L}}$ was detected in the A2780/DDP-M and COC1/DDP-M cells $(\mathrm{P}<0.05)$. In contrast, upregulation of $\mathrm{Bax}$ and $\mathrm{Bad}$ was found in the A2780/DDP-M and COC1/DDP-M cells $(\mathrm{P}<0.05)$. No differences in these proteins were noted between the A2780/DDP-B and A2780/DDP-NC cells, and between the COC1/DDP-B and COC1/DDP-NC cells (Fig. 5).
Caspase-3 activity is increased by RNA interference. After incubation with different concentrations of cisplatin, the values of $\triangle \mathrm{A} 405$ were markedly increased in the A2780/DDP-M and COC1/DDP-M cells $\left(\chi^{2}=41.345, \mathrm{P}=0.000 ; \chi^{2}=41.349\right.$, $\mathrm{P}=0.000$ ). At a higher concentration of cisplatin, a greater value for $\triangle \mathrm{A} 405$ was observed $(\mathrm{P}<0.05)$. These data indicate that the activity of caspase- 3 was increased in the A2780/DDP-M and COC1/DDP-M cells. No differences were noted between the A2780/DDP-B and A2780/DDP-NC cells, and between the COC1/DDP-B and COC1/DDP-NC cells (Fig. 6).

\section{Discussion}

Platinum compounds are the mainstay of chemotherapy for ovarian cancer, particularly for advanced patients. Cisplatin, a conventional chemotherapy drug, has long-term clinical 

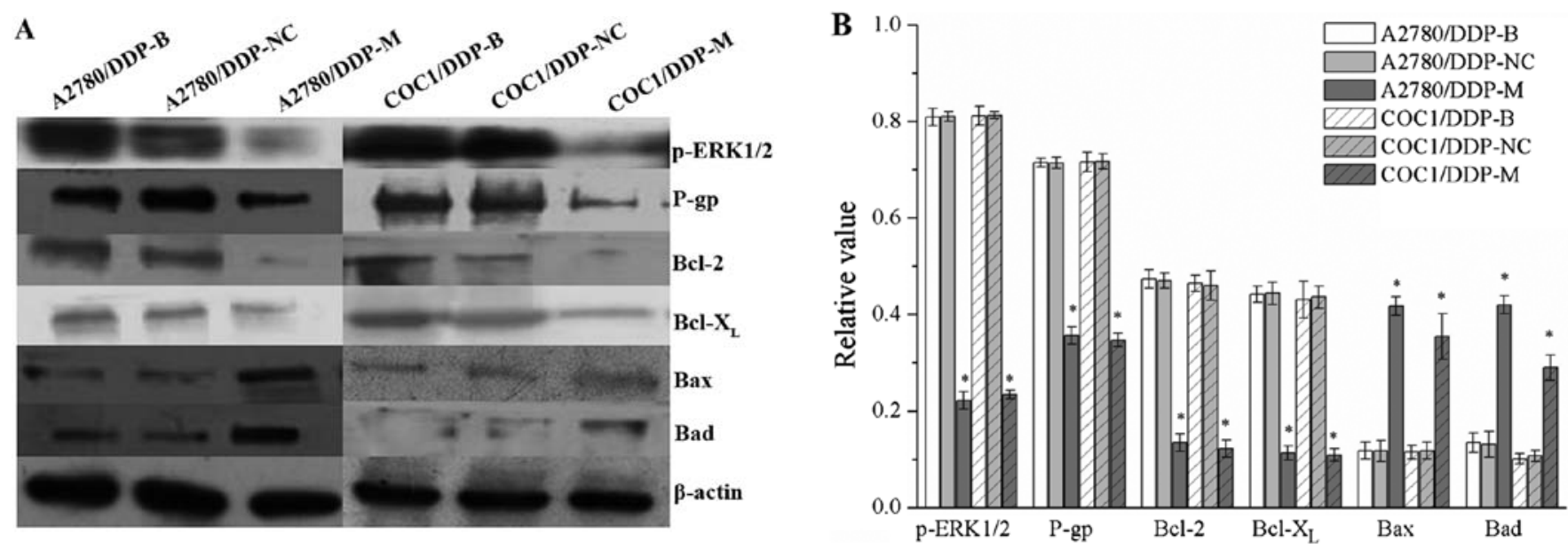

Figure 5. Expression levels of p-ERK1/2, P-gp, Bcl-2, Bcl- $\mathrm{X}_{\mathrm{L}}$, Bax and Bad proteins following MACC1 knockdown as detected by western blotting. (A) Expression levels of p-ERK1/2, P-gp, Bcl-2, Bcl- $\mathrm{X}_{\mathrm{L}}$, Bax and Bad proteins as detected by western blotting in the different cell groups. (B) Histogram shows the relative values of p-ERK1/2, P-gp, Bcl-2, Bcl-XL, Bax and Bad proteins determined by western blotting. Each bar represents the mean \pm SD. ${ }^{*} \mathrm{P}<0.05$ compared with the blank and negative control groups.

$\mathbf{A}$

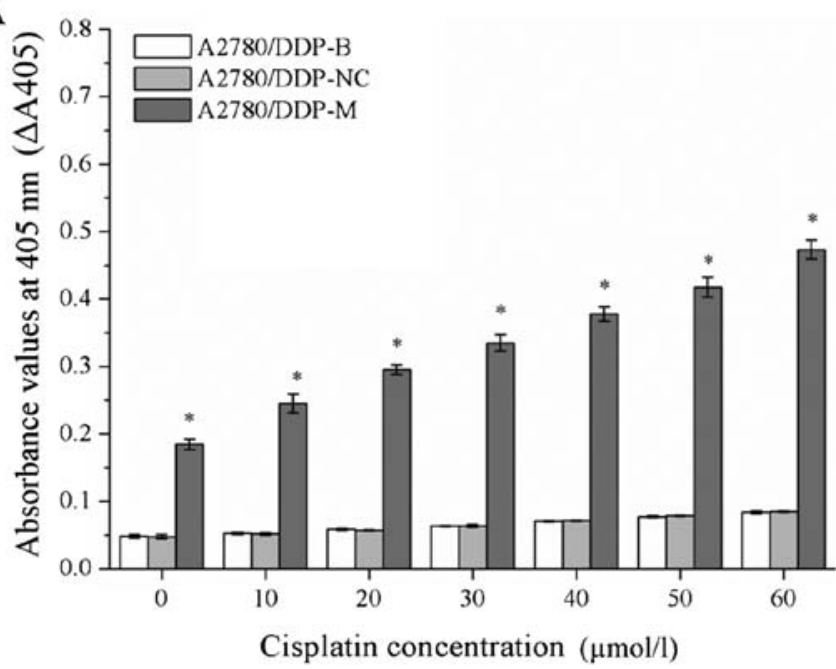

B

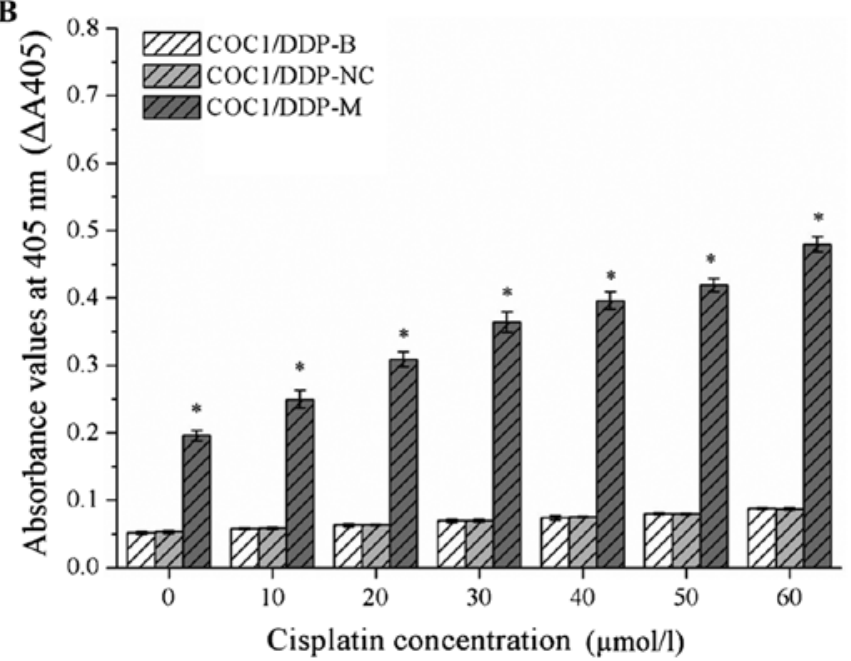

Figure 6. The values of $\Delta \mathrm{A} 405$ as determined by a spectrophotometer in the different cell groups following treatment with the different concentrations of cisplatin, respectively. The value of $\Delta \mathrm{A} 405$ (absorbance value of the sample at $405 \mathrm{~nm}$ minus the absorbance value of the blank control at $405 \mathrm{~nm}$ ) represents the activity of caspase-3. (A) Histogram represents $\Delta \mathrm{A} 405$ values in the different A2780/DDP cells. Each bar represents the mean \pm SD. ${ }^{*} \mathrm{P}<0.05$ compared with the blank and negative control groups. (B) Histogram represents $\Delta \mathrm{A} 405$ values in the different $\mathrm{COC} 1 / \mathrm{DDP}$ cells. Each bar represents the mean $\pm \mathrm{SD}$. ${ }^{*}<0.05$ compared with the blank and negative control groups.

application in ovarian cancer (14). Unfortunately, intrinsic or acquired platinum resistance remains a critical obstacle for chemotherapy treatment of epithelial ovarian cancer. After tumor cytoreductive surgery, only $70-80 \%$ of ovarian cancer cases are responsive to platinum combined chemotherapy (15).

MACC1 has been found to be associated with invasion and metastasis in numerous types of malignant tumors. Our previous studies showed that MACC1 mRNA and protein were overexpressed in ovarian cancer tissues and cells. Inhibition of MACC1 by RNA interference suppressed the invasion and metastatic potential of ovarian carcinoma cells in vitro and in vivo, and the antitumor effects of MACC1 knockdown may involve the inhibition of the MEK/ERK1/2 pathways $(10,13)$.

Recently, it has been reported that small interfering RNA targeting MACC1 attenuates cisplatin resistance in tongue squamous cell carcinoma cells (16). However, another research team claimed that downregulation of MACC1 expression by RNA interference technology had no effect on cisplatin resistance in salivary adenoid cystic carcinoma cells (17). The present results showed that MACC1 was obviously downregulated in the A2780/DDP and COC1/DDP cells by RNA interference. After MACC1 knockdown, cell growth was repressed, $\mathrm{IC}_{50}$ values of cisplatin were decreased, and the cell apoptosis rate was increased in the A2780/DDP and COC1/DDP cells following treatment with different concentrations of cisplatin. These data indicate that inhibition of MACC1 improves the cisplatin sensitivity of ovarian cancer cisplatin-resistant cells, and MACC1 may be involved in the chemoresistance of cisplatin in ovarian cancer.

The MAPK-ERK1/2 pathway has been implicated in cell survival, anti-apoptosis, invasion, metastasis, angiogenesis 
and chemoresistance of malignancies, including ovarian carcinoma (18-21). P-glycoprotein (P-gp), also known as MDR1 or the ATP-binding cassette subfamily B member 1 , is involved in the drug resistance of tumor cells. P-gp is important for transporting drugs across the cell membrane to pump drugs out of the cells and to decrease intracellular drug concentrations (22). Inhibition of MDR1 or P-gp expression can enhance drug chemosensitivity in malignant tumor cells, including ovarian cancer (23-26). Chemotherapy drugs play therapeutic roles in cancer through different mechanisms, mainly by inhibition of cell growth and induction of cell apoptosis. The Bcl-2 gene family plays key roles in cell apoptosis and cancer therapy (27). $\mathrm{Bcl}-2$ and $\mathrm{Bcl}-\mathrm{X}_{\mathrm{L}}$ are important anti-apoptotic proteins; Bax and $\mathrm{Bad}$ are pro-apoptotic proteins. Overexpression of Bcl-2 leads to drug-resistance to cisplatin in ovarian tumor cells, and $\mathrm{Bcl}-2$ inhibition by gene silencing induces cell apoptosis and reverses drug resistance $(28,29)$. Caspase- 3 is the most important apoptotic protease cascade protein in the caspase family, which can implement programmed cell death under the regulation of Bcl-2 family proteins $(30,31)$.

Following MACC1 knockdown, expression levels of p-ERK1/2, P-gp, Bcl-2 and Bcl-X $\mathrm{L}_{\mathrm{L}}$ protein were obviously decreased, while expression levels of Bax and Bad were significantly increased in this study. Furthermore, caspase-3 activity was markedly increased in the MACC1-knockdown ovarian cancer cells. These results elucidate the possible mechanisms of MACC1 involved in the cisplatin-resistance of ovarian cancer cells. These mechanisms may include the regulation of P-gp expression through the ERK1/2 signaling pathway, which affects the expression of pro-apoptotic and anti-apoptotic proteins, and the activity of caspase-3 downstream.

In conclusion, the present study demonstrated that suppression of MACC1 improves the chemosensitivity of cisplatin in epithelial ovarian cancer cells, which may be through regulation of the ERK1/2 signaling pathway and P-gp and its downstream apoptotic proteins.

\section{Acknowledgements}

We thank the Clinical Medicine Key Disciplines Laboratory of Henan Province for assistance with the experiments. Our work was supported by the Medical Key Scientific Research Project of Henan Province (122102310545) and the Hospital Youth Fund Project of the First Affiliated Hospital of Zhengzhou University.

\section{References}

1. Ledermann JA and Kristeleit RS: Optimal treatment for relapsing ovarian cancer. Ann Oncol 21 (Suppl 7): vii218-vii222, 2010.

2. Schorge JO, Modesitt SC, Coleman RL, Cohn DE, Kauff ND, Duska LR and Herzog TJ: SGO White Paper on ovarian cancer: Etiology, screening and surveillance. Gynecol Oncol 119: 7-17, 2010.

3. Parmar MK, Ledermann JA, Colombo N, du Bois A, Delaloye JF, Kristensen GB, Wheeler S, Swart AM, Qian W, Torri V, et al ICON and AGO Collaborators: Paclitaxel plus platinum-based chemotherapy versus conventional platinum-based chemotherapy in women with relapsed ovarian cancer: The ICON4/AGO-OVAR-2.2 trial. Lancet 361: 2099-2106, 2003.

4. Bookman MA: The addition of new drugs to standard therapy in the first-line treatment of ovarian cancer. Ann Oncol 21 (Suppl 7): vii211-vii217, 2010.
5. Siegel R, Naishadham D and Jemal A: Cancer statistics, 2013. CA Cancer J Clin 63: 11-30, 2013.

6. Shirahata A, Shinmura K, Kitamura Y, Sakuraba K, Yokomizo K, Goto T, Mizukami H, Saito M, Ishibashi K, Kigawa G, et al: MACC1 as a marker for advanced colorectal carcinoma. Anticancer Res 30: 2689-2692, 2010.

7. Shirahata A, Sakata M, Kitamura Y, Sakuraba K, Yokomizo K, Goto T, Mizukami H, Saito M, Ishibashi K, Kigawa G, et al: MACC 1 as a marker for peritoneal-disseminated gastric carcinoma. Anticancer Res 30: 3441-3444, 2010.

8. Shimokawa H, Uramoto H, Onitsuka T, Chundong G, Hanagiri T, Oyama T and Yasumoto K: Overexpression of MACC1 mRNA in lung adenocarcinoma is associated with postoperative recurrence. J Thorac Cardiovasc Surg 141: 895-898, 2011.

9. Shirahata A, Fan W, Sakuraba K, Yokomizo K, Goto T, Mizukami H, Saito M, Ishibashi K, Kigawa G, Nemoto H, et al: MACC 1 as a marker for vascular invasive hepatocellular carcinoma. Anticancer Res 31: 777-780, 2011.

10. Zhang RT, Shi HR, Huang HL, Chen ZM, Liu HN and Yuan ZF: Expressions of MACC1, HGF, and C-met protein in epithelial ovarian cancer and their significance. Nan Fang Yi Ke Da Xue Xue Bao 31: 1551-1555, 2011 (In Chinese).

11. Wang G, Kang MX, Lu WJ, Chen Y, Zhang B and Wu YL: MACC1: A potential molecule associated with pancreatic cancer metastasis and chemoresistance. Oncol Lett 4: 783-791, 2012.

12. Shang C, Hong Y, Guo Y, Liu YH and Xue YX: Influence of the MACC1 gene on sensitivity to chemotherapy in human U251 glioblastoma cells. Asian Pac J Cancer Prev 16: 195-199, 2015.

13. Zhang R, Shi H, Chen Z, Wu Q, Ren F and Huang H: Effects of metastasis-associated in colon cancer 1 inhibition by small hairpin RNA on ovarian carcinoma OVCAR-3 cells. J Exp Clin Cancer Res 30: 83, 2011.

14. Chen S, Jiao JW, Sun KX, Zong ZH and Zhao Y: MicroRNA-133b targets glutathione $S$-transferase $\pi$ expression to increase ovarian cancer cell sensitivity to chemotherapy drugs. Drug Des Devel Ther 9: 5225-5235, 2015.

15. Zhang Z, Xie Z, Sun G, Yang P, Li J, Yang H, Xiao S, Liu Y, Qiu H, Qin L, et al: Reversing drug resistance of cisplatin by hsp90 inhibitors in human ovarian cancer cells. Int J Clin Exp Med 8: 6687-6701, 2015.

16. Li HF, Liu YQ, Shen ZJ, Gan XF, Han JJ, Liu YY, Li HG and Huang ZQ: Downregulation of MACC1 inhibits invasion, migration and proliferation, attenuates cisplatin resistance and induces apoptosis in tongue squamous cell carcinoma. Oncol Rep 33: 651-660, 2015.

17. Li H, Liao X, Liu Y, Shen Z, Gan X, Li H and Huang Z: The expression of MACC1 and its role in the proliferation and apoptosis of salivary adenoid cystic carcinoma. J Oral Pathol Med 44: 810-817, 2015.

18. Seger R and Krebs EG: The MAPK signaling cascade. FASEB J 9: 726-735, 1995.

19. Nicosia SV, Bai W, Cheng JQ, Coppola D and Kruk PA: Oncogenic pathways implicated in ovarian epithelial cancer. Hematol Oncol Clin North Am 17: 927-943, 2003.

20. Jin W, Wu L, Liang K, Liu B, Lu Y and Fan Z: Roles of the PI-3K and MEK pathways in Ras-mediated chemoresistance in breast cancer cells. Br J Cancer 89: 185-191, 2003.

21. Montagut $C$ and Settleman J: Targeting the RAF-MEK-ERK pathway in cancer therapy. Cancer Lett 283: 125-134, 2009.

22. Andorfer $P$ and Rotheneder H: Regulation of the MDR1 promoter by E2F1 and EAPP. FEBS Lett 587: 1504-1509, 2013.

23. Chen J, Ding Z, Peng Y, Pan F, Li J, Zou L, Zhang Y and Liang H: HIF-1 $\alpha$ inhibition reverses multidrug resistance in colon cancer cells via downregulation of MDR1/P-glycoprotein. PLoS One 9: e98882, 2014.

24. Wang Q, Wang Z, Chu L, Li X, Kan P, Xin X, Zhu Y and Yang P: The effects and molecular mechanisms of miR-106a in multidrug resistance reversal in human glioma U87/DDP and U251/G cell lines. PLoS One 10: e0125473, 2015.

25. Januchowski R, Wojtowicz K, Sujka-Kordowska P, Andrzejewska M and Zabel M: MDR gene expression analysis of six drug-resistant ovarian cancer cell lines. Biomed Res Int 2013: 241763, 2013.

26. Zhang T, Guan M, Jin HY and Lu Y: Reversal of multidrug resistance by small interfering double-stranded RNAs in ovarian cancer cells. Gynecol Oncol 97: 501-507, 2005. 
27. Thomas S, Quinn BA, Das SK, Dash R, Emdad L, Dasgupta S, Wang XY, Dent P, Reed JC, Pellecchia M, et al: Targeting the Bcl-2 family for cancer therapy. Expert Opin Ther Targets 17: 61-75, 2013.

28. Babu A, Wang Q, Muralidharan R, Shanker M, Munshi A and Ramesh R: Chitosan coated polylactic acid nanoparticle-mediated combinatorial delivery of cisplatin and siRNA/Plasmid DNA chemosensitizes cisplatin-resistant human ovarian cancer cells. Mol Pharm 11: 2720-2733, 2014.

29. Yang HL, Lin KY, Juan YC, Kumar KJ, Way TD, Shen PC, Chen SC and Hseu YC: The anti-cancer activity of Antrodia camphorata against human ovarian carcinoma (SKOV-3) cells via modulation of HER-2/neu signaling pathway. J Ethnopharmacol 148: 254-265, 2013.
30. Galluzzi L, Kepp O and Kroemer G: Caspase-3 and prostaglandins signal for tumor regrowth in cancer therapy. Oncogene 31: 2805-2808, 2012.

31. Zhang SD, Shan L,Li W, Li HL and Zhang WD: Isochamaejasmin induces apoptosis in leukemia cells through inhibiting Bcl-2 family proteins. Chin J Nat Med 13: 660-666, 2015. 